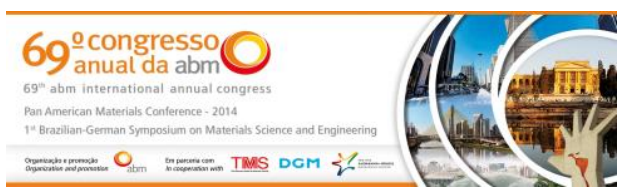

Tema: Comportamento de Materiais em Temperaturas Elevadas

\title{
MECANISMOS DE DEFORMAÇÃO PLÁSTICA POR FLUÊNCIA APLICÁVEIS A CLASSE DOS AÇOS Cr-Mo*
}

\section{Resumo}

Aline Raquel Vieira Silva ${ }^{1}$ Ana Emilia Diniz Silva Guedes²

A seleção e o emprego de materiais para serviços sob tensão e temperaturas elevadas envolvem diversos problemas e, portanto o estudo dos mecanismos de deformação plástica por fluência se torna extremamente desejável. Os aços ferríticos vêm sendo extensivamente usados na indústria, em componentes críticos de plantas petroquímicas e de geração de energia devido principalmente à sua elevada resistência à fluência. Em tais circunstâncias, a deformação por fluência é importante na determinação do tempo de vida do componente. Dentre os aços resistentes a altas temperaturas, a escolha pelos aços ferríticos Cr-Mo se destaca pela excelente resistência à fluência, tenacidade e resistência à corrosão, além de uma expansão térmica relativamente baixa, o que os tornam mais atrativos em aplicações com ciclos térmicos. O desenvolvimento desses aços ocorreu através de modificações na composição química, dando origem a diferentes gerações de aços com o objetivo de aumentar a resistência à fluência. A deformação por fluência até a ruptura varia com a temperatura, tensão e tempo de exposição devido à precipitação, alteração de morfologia e distribuição de precipitados. Visando compreender o desempenho dos aços ferríticos Cr-Mo em aplicações de alta temperatura a nível microestrutural, foi realizado o estudo dos mecanismos de deformação plástica por fluência desses aços, pertencentes à norma ASTM A-335, submetidos a tratamento térmico de $500^{\circ} \mathrm{C}$ a $600^{\circ} \mathrm{C}$

Palavras-chave:Deformação plástica; Fluência; Aços Cr-Mo.

\section{MECHANISMS OF PLASTIC DEFORMATION CREEP APPLIED TO THE CLASS OF Cr-Mo STEELS}

\begin{abstract}
The selection and use of materials for services under stress and high temperatures involves various problems, and therefore study the mechanisms of plastic deformation by creep becomes extremely desirable. The ferritic steels are being used extensively in industry, the critical components of petrochemical plants and power generation mainly due to its high creep resistance. In such circumstances, the creep flow is important in determining the life of the component. Among the steels resistant to high temperatures, the choice for ferritic $\mathrm{Cr}-\mathrm{Mo}$ stands for excellent creep resistance, toughness and corrosion resistance, and a relatively low thermal expansion, which make them more attractive in applications with thermal cycles. The development of these steels occurred through changes in chemical composition, giving rise to different generations of steels in order to increase the creep resistance. The creep strain at break varies with the temperature, voltage and exposure time due to precipitation, change morphology and distribution of precipitates. To understand the performance of ferritic $\mathrm{Cr}$-Mo in high temperature applications the microstructural level, we carried out the study of the mechanisms of plastic deformation creep of these steels belonging to ASTM A-335, heat treated $500^{\circ} \mathrm{C}$ to $600^{\circ} \mathrm{C}$.

Keywords: Plastic deformation; Creep; Cr-Mo steels.

1 Engenheira de Materiais, Mestranda do Programa de Pós Graduação em Engenharia Metalúrgica e de Materiais COPPE, UFRJ, Rio de Janeiro, RJ, Brasil.

2 Engenheira de Materiais, Doutoranda do Programa de Pós Graduação em Engenharia Mecânica, UFRN, Natal, RN, Brasil.
\end{abstract}

* Contribuição técnica ao 69ำ Congresso Anual da ABM - Internacional e ao 14ํㅡㄹ ENEMET - Encontro Nacional de Estudantes de Engenharia Metalúrgica, de Materiais e de Minas,21 a 25 de julho de 2014, São Paulo, SP, Brasil. 


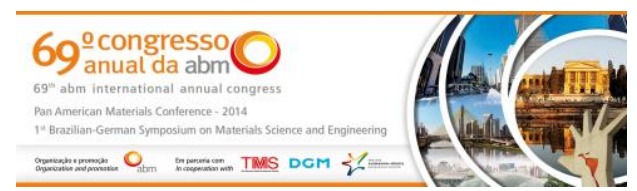

\section{INTRODUÇÃO}

A resistência dos metais diminui com o aumento da temperatura, uma vez que a mobilidade dos átomos cresce rapidamente, e os processos controlados por difusão exercem um efeito muito significante sobre as propriedades mecânicas a altas temperaturas, como também resultam numa maior mobilidade das discordâncias devido ao mecanismo de escalagem, que se torna importante devido à maior facilidade de difusão e também porque a concentração de lacunas em equilíbrio aumenta com a temperatura. Em alguns metais, com o aumento da temperatura, 0 sistema de deslizamento muda, ou são introduzidos sistemas de deslizamento adicionais. A deformação nos contornos de grão torna-se uma possibilidade adicional na deformação dos metais a temperaturas elevadas [1].

A fluência é uma propriedade de grande importância especialmente na seleção de materiais para operar a altas temperaturas. A velocidade com que a deformação ocorre depende tanto da temperatura a que o material está submetido como do nível de tensão aplicada, e quanto mais longos forem esses tempos, ocorrerão transformações metalúrgicas como o crescimento do grão, recuperação, recristalização e superenvelhecimento.

Segundo Mao et al. [2], a fluência é um dos principais mecanismos de dano a materiais que operam a temperaturas elevadas. A uma temperatura superior a $30 \%$ da temperatura de fusão absoluta do material uma significante dependência do tempo é observada nos materiais metálicos. Para Souza [3] aplicações a altas temperaturas demandam ligas metálicas resistentes a este agressivo ambiente principalmente no desenvolvimento para emprego em mísseis, foguetes, aeronaves de alta velocidade e plantas nucleares, nestes locais os materiais podem ser utilizados a temperaturas superiores a $1000^{\circ} \mathrm{C}$.

A fluência envolve diferentes mecanismos que atuam em paralelo e que somam seus efeitos. Segundo Miranda et al. [4] dependendo do material, das suas características estruturais, da intensidade do campo de tensões e da temperatura, um desses mecanismos assume o controle do processo de fluência.

Este trabalho tem como objetivo apresentar os mecanismos de deformação plástica por fluência aplicado a classe dos aços Cr-Mo, pertencentes à norma ASTM A-335, submetidos a tratamento térmico de 500 a $600^{\circ} \mathrm{C}$.

\subsection{Fluência}

Fluência é definida como o fenômeno de deformação plástica, lenta e progressiva de materiais metálicos, que ocorre à medida que a temperatura aumenta, sob carga constante. O aumento da temperatura acentua o fenômeno, porque a deformação plástica torna-se progressivamente mais fácil de iniciar-se e de continuar [5]. A fluência só é possível porque os obstáculos à deformação podem ser vencidos pela ação combinada das flutuações térmicas e da tensão. A deformação plástica ocorre sob carga ou tensão constante, em temperaturas elevadas (T>0,5THF). A curva da Figura 1 ilustra a forma idealizada da curva de fluência a carga constante e a tensão constante, onde apresenta três estágios.

Fluência primária (Região I) - mecanismo de encruamento predominante, que se dá pelo deslizamento de discordâncias. Representa uma região de taxa de deformação decrescente. Este estágio é um período de fluência transiente no qual a resistência do material à fluência aumenta devido à sua própria deformação [1].

\footnotetext{
* Contribuição técnica ao $69^{\circ}$ Congresso Anual da ABM - Internacional e ao 14ํㅡㄹ ENEMET - Encontro Nacional de Estudantes de Engenharia Metalúrgica, de Materiais e de Minas,21 a 25 de julho de 2014, São Paulo, SP, Brasil.
} 

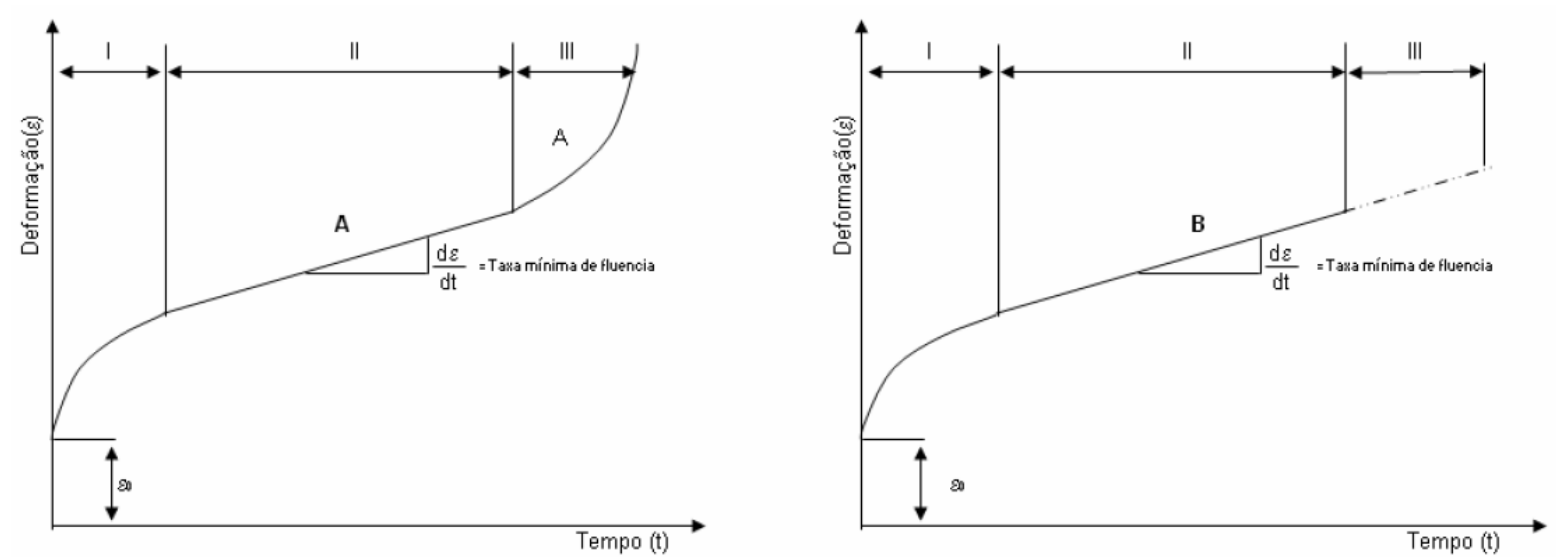

Figura 1. Curvas típicas de fluência de um material em condições de carga (Curva $A$ ) e tensão (curva B) constantes. (Adaptado de [6])

Fluência secundária (Região II) - ou fluência em estado de equilíbrio, é um período de taxa de fluência aproximadamente constante que resulta de um processo competitivo entre mecanismos de encruamento e de recuperação. O valor médio da taxa de fluência durante este estágio é denominado taxa mínima de fluência [1]. A recuperação significa a libertação de discordâncias dos obstáculos ou barreiras (empilhamento de discordâncias, precipitados, etc.) por meio de escalagem ou deslizamento de discordâncias. A escalagem das discordâncias é feita por absorção e emissão de lacunas [3].

Fluência terciária (Região III) - a recuperação é predominante. Iniciam-se os micromecanismos de fratura, seja devido à formação de pescoço, seja por formação de vazios internos, destacando o deslizamento de contorno de grão. Esta fase ocorre frequentemente associada com variações metalúrgicas tais como crescimento de partículas de precipitado, deslizamento de contorno de grão, recristalização, ou variações difusionais nas fases presentes [1].

As ligas metálicas que sofrem fratura intergranular típica da fluência a temperaturas elevadas, devem apresentar preferivelmente granulação grosseira. A temperatura em que ocorre a inversão do comportamento do contorno do grão, no sentido de facilitar o movimento das discordâncias e para o qual a fratura muda de intragranular para intergranular é chamada de temperatura equicoesiva. Para os aços de baixo carbono, essa temperatura é de ordem de $450^{\circ} \mathrm{C}$, sendo maior para certos aços-ligas [5].

\subsection{Mecanismos de Deformação por Fluência}

Diversos mecanismos teóricos foram propostos para explicar o comportamento da fluência para vários materiais e a literatura registra inúmeras teorias que procuram explicar este comportamento $[1,7,8]$. Os principais mecanismos de deformação por fluência são: deslizamento de discordâncias, fluência por discordâncias, fluência por difusão e deslizamento de contorno grão. Porém, Miranda [4] propõe que as teorias de maior aceitação atualmente dizem respeito ao deslizamento e escalagem das discordâncias e os efeitos da difusão na fluência.

O deslizamento de discordâncias ocorre pela geração e movimentação de discordâncias em seus planos preferenciais de deslizamento sendo os obstáculos superados por ativação térmica. A taxa de fluência é função direta da resistência à movimentação de discordâncias. Todos os cristais reais contem uma rede de discordâncias que cresce em complexidade à medida que aumenta a deformação

\footnotetext{
* Contribuição técnica ao $69^{\circ}$ Congresso Anual da ABM - Internacional e ao 14ํㅡㄹ ENEMET - Encontro Nacional de Estudantes de Engenharia Metalúrgica, de Materiais e de Minas,21 a 25 de julho de 2014, São Paulo, SP, Brasil.
} 
plástica [8]. Esse mecanismo só se manifesta acima de uma tensão crítica, e como essa tensão é em geral relativamente alta, esse mecanismo é de importância secundária para aplicações industriais comuns [4].

A Fluência por discordâncias envolve principalmente o mecanismo de escalagem, assistida pela presença massiva de defeitos pontuais em equilíbrio termodinâmico. A escalagem de discordância ocorre através da difusão de lacunas ou átomos intersticiais para a discordância, ou partindo dela. Como a escalagem é um processo controlado por difusão, ela é termicamente ativada e corre mais facilmente a altas temperaturas. Na deformação a baixa temperatura estas discordâncias interfeririam umas com as outras e bloqueariam as fontes, o que não se verifica a altas temperaturas porque ocorre a escalagem que permite que as fontes continuem operando [1]. A taxa mínima de fluência depende da frequência com que ocorrem flutuações de posição, originadas pela excitação térmica, e assim capazes de permitir o movimento dos átomos ultrapassando os obstáculos a partir de suas posições de equilíbrio [4].

A fluência por difusão depende do fluxo de lacunas ou intersticiais que são orientados pelo campo de tensão que atua no material. É um processo termicamente ativado. Dependendo das condições de temperatura e tensão, o fluxo de defeitos pode ocorrer preferencialmente através do cristal ou através dos contornos de grão. Segundo Kim et al. [9] a fluência por difusão é a deformação causada devido ao transporte de massa direcionado por uma tensão ao longo dos grãos ou por seus contornos a baixas tensões aplicadas.

Há dois tipos de mecanismos diferentes de fluência por difusão, o mecanismo de fluência de Nabarro-Herring e fluência de Coble. A Fluência de Nabarro-Herring ocorre em temperaturas elevadas e tensões baixas, e a difusão se dá no interior dos grãos. Segundo Miranda [4], esse mecanismo de Nabarro-Herring não envolve movimentação das discordâncias. Já a fluência de Coble ocorre em temperaturas mais baixas, e a difusão é feita pelos contornos de grão, visto que o caminho médio do contorno de grão em baixas temperaturas é maior. Em temperaturas elevadas, a ativação térmica é suficiente para promover difusão dentro do grão [10].

O deslizamento dos contornos de grão é um processo de cisalhamento que ocorre na direção do contorno de grão e é favorecido pelo aumento da temperatura e/ou pelo decréscimo da taxa de deformação. Para Miranda [4], o deslizamento do contorno de grão resulta da conjugação da fluência por difusão e fluência por discordâncias sendo acompanhado por deformação no interior dos grãos como condição para continuidade estrutural. De acordo com Dieter [1], partes de um contorno de grão ganham mobilidade promovendo alongamento dos mesmos. Para acomodar a mudança de forma dos grãos pode ser necessária a formação de "dobras" nas junções dos contornos. O mecanismo de deslizamento de contorno é de extrema importância na iniciação de micromecanismos de fratura por fluência.

\subsection{Ligas Resistentes à Fluência}

No desenvolvimento de ligas resistentes à fluência existem dois problemas: a resistência à deformação dos grãos e dos contornos de grão deve ser aumentada, enquanto a recuperação e os efeitos de amolecimento devem ser minimizados. Nas temperaturas onde a maioria das ligas comerciais é usada, a deformação plástica pode ser controlada pela movimentação de discordâncias dentro dos grãos. A maioria dos métodos conhecidos de endurecimento dos metais é, portanto, aplicável às ligas

\footnotetext{
* Contribuição técnica ao $69^{\circ}$ Congresso Anual da ABM - Internacional e ao 14ํㅡㄹ ENEMET - Encontro Nacional de Estudantes de Engenharia Metalúrgica, de Materiais e de Minas,21 a 25 de julho de 2014, São Paulo, SP, Brasil.
} 
resistentes a fluência, como o endurecimento por solução solida, por precipitação e por encruamento [8].

Em geral, as ligas resistentes ao calor comerciais apresentam uma matriz que é uma solução solida. Essa matriz é normalmente mais resistente à fluência do que um metal puro, porque os elementos em solução sólida tornam mais difícil o movimento de discordâncias pelo reticulado. O mecanismo básico de aumento da resistência está provavelmente associado à formação de atmosferas de átomos de soluto ao redor das discordâncias. Na maioria dos casos, os grãos da matriz são tornados ainda mais resistentes pelo endurecimento por precipitação. Uma deformação plástica previa da matriz é outro método de aumentar a resistência à alta temperatura. Esse trabalho a frio para aumentar a resistência à fluência deve ser feito a uma temperatura abaixo daquela onde o metal se recristaliza durante a deformação [8].

A gama de aços disponíveis inclui os ferriticos/martensíticos e os austeníticos. Dentro do primeiro grupo, eles podem dividi-los por teor de cromo $(2,25 \% \mathrm{Cr}, 9 \% \mathrm{Cr}$ e $12 \% \mathrm{Cr}$ ). Os aços ferriticos apresentam, em geral, como microestrutura na temperatura de trabalho, martensita revenida, bainita ou mesmo ferrita/perlita, dependendo do tipo de tratamento térmico e os teores de liga.

Os aços-liga são obtidos por trabalho mecânico ou por fundição, e são fabricados em forma de chapas, tiras, forjados, barras, tubos e arames. Os primeiros são os aços ao cromo ou ao cromo-níquel, conforme o tipo de aço, o teor de cromo pode ir de 4 a $27 \%$ e o teor de níquel de 8 a $36 \%$. Alguns aços contem molibdênio até $3 \%$, titânio e nióbio como elementos de liga [3].

Os aços ferríticos foram os primeiros a serem desenvolvidos para resistirem à fluência. Eles são aços-carbono com altos teores de cromo e molibdênio, que forma carbonetos complexos precipitados. Essas ligas são limitadas ao uso até cerca de $540^{\circ} \mathrm{C}$, devido à instabilidade dos seus carbonetos e da suscetibilidade à corrosão em temperaturas mais altas. Os aços inoxidáveis austeníticos foram posteriormente utilizados a até $650^{\circ} \mathrm{C}$ [3]. Os ferríticos são os mais baratos, mas são difíceis de soldar. A principal vantagem dos ferríticos sobre os austeníticos são a sua maior resistência à oxidação. As superligas são baseadas em ligas austeníticas de níquel ou cobalto, contendo cromo para conferir maior resistência à oxidação. Resistem a temperaturas superiores a $700^{\circ} \mathrm{C}$, devido à dispersão estável de suas partículas de segunda fase (carbonetos complexos de molibdênio, tungstênio e nióbio), no caso de ligas à base de cobalto. Existem ainda ligas com combinações de elementos como Ni-Cr-Mo-Fe (Hastelloys), $\mathrm{Ni}$-Mo-Cr-Fe e as ligas à base de cromo (ligas $\mathrm{Cr}-\mathrm{Fe}-\mathrm{W}$ e Cr-Fe-Mo) para a utilização em alta temperatura [3].

\subsection{Aços Cr-Mo}

Os aços do grupo Cr-Mo são amplamente utilizados em aplicações diversas na indústria química, petrolífera ou de gás, na indústria nuclear e usinas de geração elétrica. Podem ser encontrados em componentes como vasos de pressão, trocadores de calor, caldeiras, válvulas, rotores de turbinas, tubulações, partes estruturais, entre outras aplicações que envolvem exposição a altas temperaturas, onde ser requer resistência à fluência promovida pelas adições de molibdênio e a melhoria da resistência à corrosão promovida pelo cromo. Comercialmente estão disponíveis sobre a forma de peças forjadas, tubos, canos, peças fundidas ou chapas $[11,12]$.

Com todos os avanços de fabricação e manufatura dos aços da classe Cr-Mo e conhecidas as suas propriedades mecânicas é comum que estes aços sejam os primeiros a serem considerados em cálculos de projeto. Os materiais que apresentam

* Contribuição técnica ao 69 Congresso Anual da ABM - Internacional e ao 14ํㅡㄹ ENEMET - Encontro Nacional de Estudantes de Engenharia Metalúrgica, de Materiais e de Minas,21 a 25 de julho de 2014, São Paulo, SP, Brasil. 


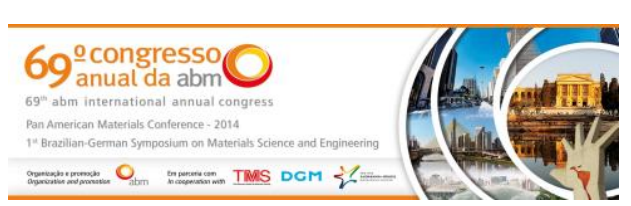

baixo coeficiente de expansão térmica e alta condutividade térmica são desejáveis, daí a preferência pelos aços ferríticos [13]. A ideia de se obter aços ferríticos com resistência mecânica a altas temperaturas, comparável ou até melhores em casos específicos, que os aços austeníticos e com menor custo de fabricação foi a motivação central do desenvolvimento inicial desta família de aços.

A Figura 2 faz um comparativo em função da resistência à fluência dos aços da classe Cr-Mo com outras grandes famílias de ligas de engenharia. Essas comparações devem ser feitas levando em consideração seus concorrentes diretos, os aços austeníticos. Essas propriedades a altas temperaturas permitem a utilização em aplicações críticas onde a maioria dos materiais estaria submetida principalmente a falhas devido aos efeitos da fluência. Em grande parte, suas propriedades a altas temperaturas são o resultado da adição criteriosa de elementos de liga e dos tratamentos térmicos pelos quais passam esses aços [14].

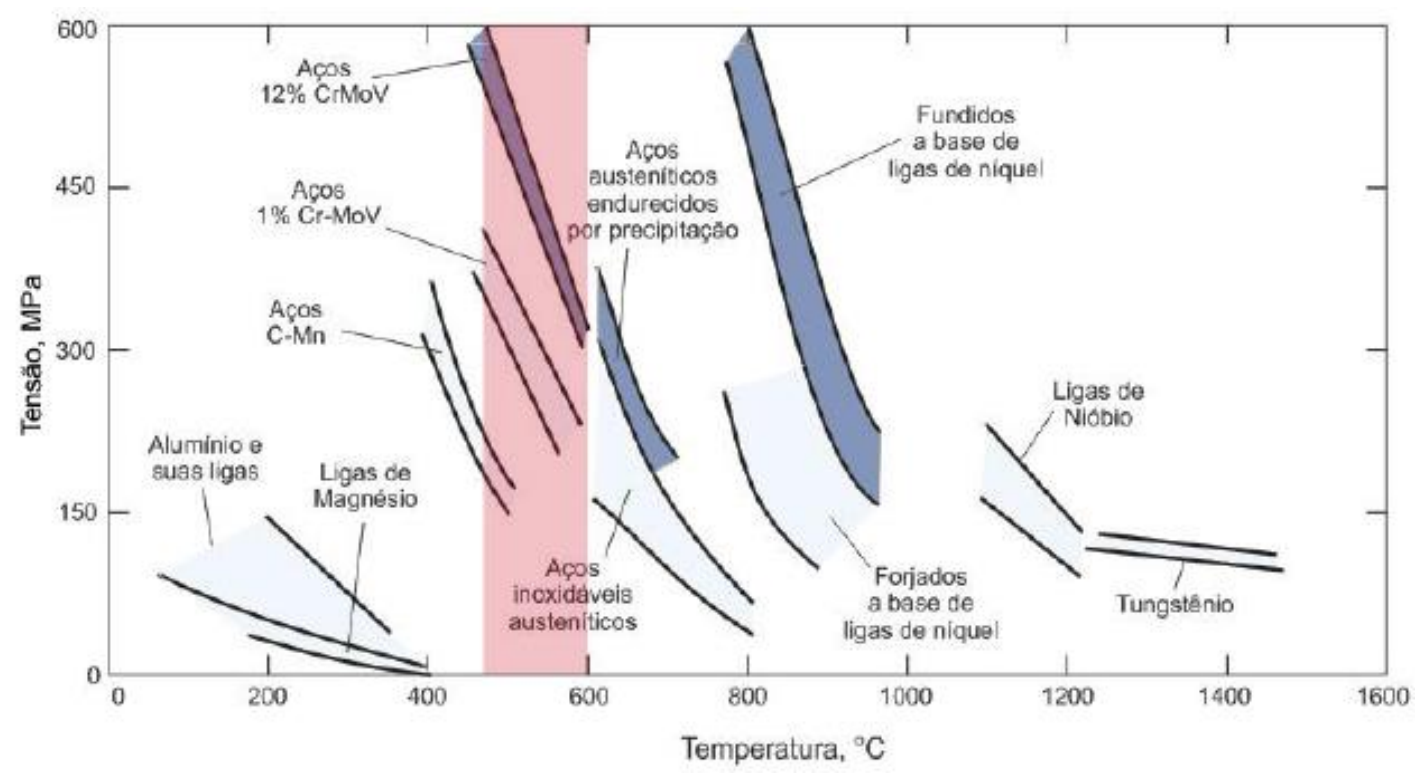

Figura 2. Tensão até a ruptura em 100 h para várias ligas. (Adaptado de [15])

A Figura 3 apresenta outro importante fator a favor da aplicação dos aços Cr-Mo resistentes a altas temperaturas, o custo notavelmente inferior aos aços austeníticos. Atualmente por questões econômicas estes aços são frequentemente aplicados na condição normalizado e revenido. O papel do revenimento nestes aços vai mais além do que somente aliviar as tensões provocadas pela transformação martensítica, a temperatura e o tempo de tratamento terão efeitos significativos sobre a estabilidade da microestrutura e também sobre a cinética de precipitação. Temperaturas mais baixas de revenimento tendem a manter alta a densidade de discordâncias favorecendo a recuperação e a recristalização da martensita.

Manter suas propriedades sobre um regime de fluência é o principal atributo dos aços Cr-Mo e essa fundamental característica é muito sensível à microestrutura inicial. Ao longo dos anos de aplicação, estudos foram desenvolvidos com o intuito de otimizar os tratamentos térmicos aplicados e as composições químicas dos aços $\mathrm{Cr}$-Mo. Essas modificações não somente alteraram suas propriedades, mas também reduziram seus custos tornando-os mais competitivos frente a outros aços que dispõem de características semelhantes.

\footnotetext{
* Contribuição técnica ao $69^{\circ}$ Congresso Anual da ABM - Internacional e ao 14ํㅡㄹ ENEMET - Encontro Nacional de Estudantes de Engenharia Metalúrgica, de Materiais e de Minas,21 a 25 de julho de 2014, São Paulo, SP, Brasil.
} 

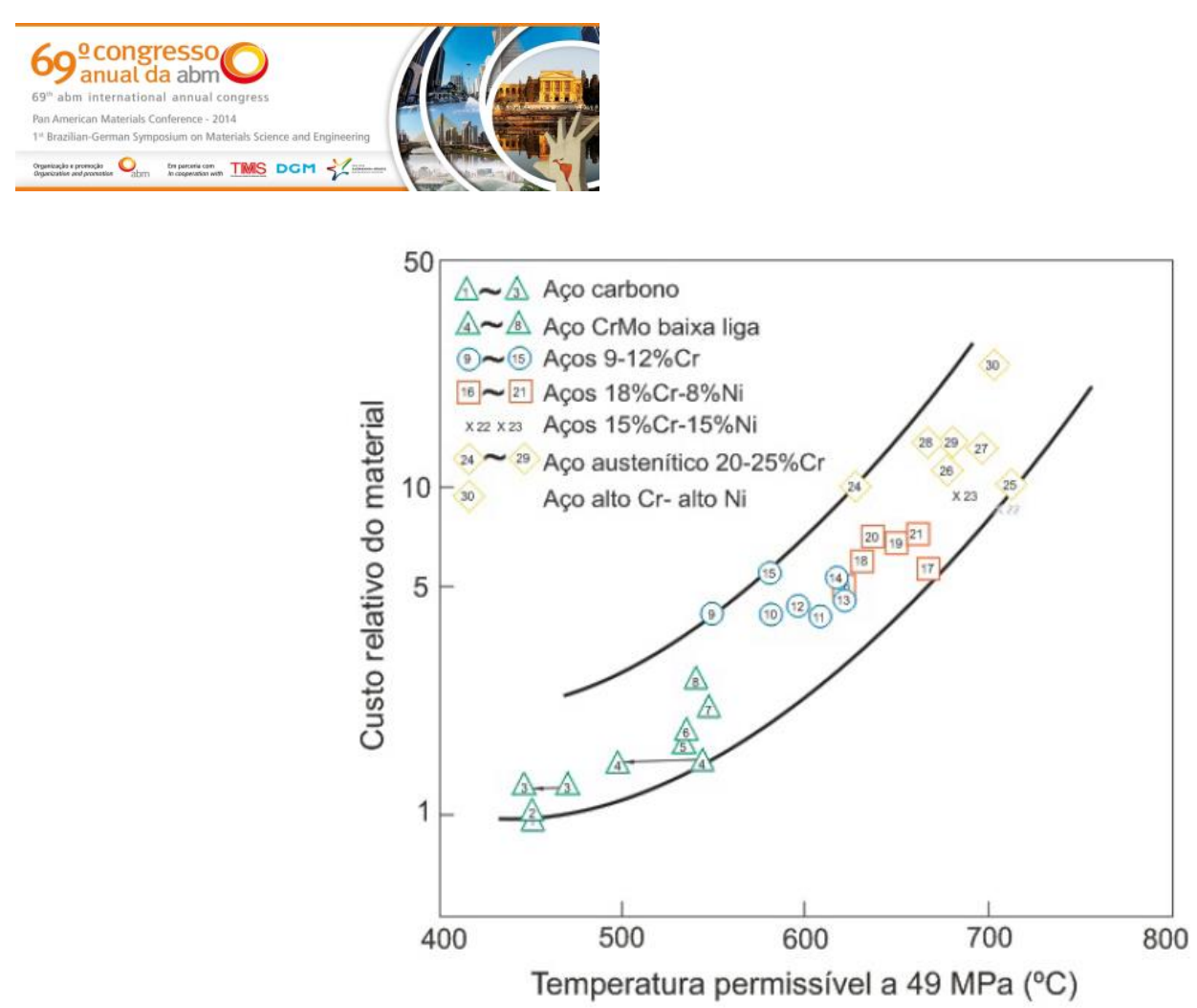

Figura 3. Relação entre temperatura de operação a $49 \mathrm{MPa}$ de pressão versus custo relativo do material. (Adaptado de [16])

A Tabela 1 abaixo lista um resumo das composições químicas de alguns aços Cr-Mo que foram padronizados de acordo com a norma ASTM (American Society for Testing and Materials). A Tabela 2 apresenta os requisitos mecânicos necessários conforme a norma ASTM.

Tabela 1. Composições químicas das classes de aços Cr-Mo conforme ASTM. (Adaptado de [17])

\begin{tabular}{|c|c|c|c|c|c|c|c|c|c|c|c|c|c|c|c|}
\hline Classe & $\mathrm{C}(\%)$ & $\mathrm{Mn}(\%)$ & $\mathrm{P}(\%)$ & $\mathrm{S}(\%)$ & Si (\%) & $\mathrm{Cr}(\%)$ & $W(\%)$ & Mo (\%) & $V(\%)$ & $\mathrm{Nb}(\%)$ & $\mathrm{Ti}(\%)$ & $N(\%)$ & B (\%) & $\mathrm{Al}(\%)$ & $\mathrm{Ni}(\%)$ \\
\hline $\mathrm{T} / \mathrm{P} 22$ & 0,15 & 0,60 & 0,025 & 0,025 & 0,50 & 2,60 & & 1,13 & & & & & & & \\
\hline $\mathrm{T} / \mathrm{P} 23$ & 0,10 & 0,60 & 0,030 & 0,010 & 0,50 & 2,60 & 1,75 & 0,30 & 0,30 & 0,08 & & 0,030 & 0,006 & 0,03 & \\
\hline \multirow{2}{*}{$T / P 24$} & 0,05 & 0,30 & - & - & 0,15 & 2,20 & & 0,90 & 0,20 & & 0,06 & - & 0,0015 & - & \\
\hline & 0,10 & 0,70 & 0,020 & 0,010 & 0,45 & 2,60 & & 1,10 & 0,30 & & 0,10 & 0,012 & 0,0070 & 0,02 & \\
\hline \multirow{2}{*}{ T/P911 } & 0,09 & 0,30 & - & - & 0,10 & 8,50 & 0,90 & 0,90 & 0,18 & 0,06 & & 0,040 & 0,0003 & - & - \\
\hline & 0,13 & 0,60 & 0,020 & 0,010 & 0,50 & 9,50 & 1,10 & 1,10 & 0,25 & 0,10 & & 0,090 & 0,006 & 0,04 & 0,04 \\
\hline \multirow{2}{*}{ T/P92 } & 0,07 & 0,30 & - & - & - & 8,50 & 1,50 & 0,30 & 0,15 & 0,04 & & 0,030 & 0,001 & - & - \\
\hline & 0,13 & 0,60 & 0,020 & 0,010 & 0,50 & 9,50 & 2,00 & 0,60 & 0,25 & 0,09 & & 0,070 & 0,006 & 0,04 & 0,04 \\
\hline
\end{tabular}

Tabela 2. Propriedades mecânicas para composições de aços Cr-Mo conforme ASTM. (Adaptado de [17])

\begin{tabular}{llllll}
\hline Classe & & $0,2 \%$ LE (MPa) & LR (MPa) & Along. (\%) & HB (Máx) \\
\hline T/P22 & Min. & 205 & 415 & 30 & 163 \\
T/P23 & Min. & 400 & 510 & 20 & 220 \\
T/P24 & Min. & 415 & 585 & 20 & 250 \\
T/P91 & Min. & 415 & 585 & 20 & 250 \\
T/P911 & Min. & 440 & 620 & 20 & 250 \\
T/P92 & Min. & 440 & 620 & 20 & 250 \\
\hline
\end{tabular}

O carbono é o elemento que possui uma forte influência para o aumento da resistência à fluência das ligas, e quanto mais severo forem às condições de envelhecimento, menor é o efeito endurecedor do carbono na matriz, e como a formação de carbonetos está envolvida com todas as propriedades mecânicas em altas temperaturas, 0

\footnotetext{
* Contribuição técnica ao $69^{\circ}$ Congresso Anual da ABM - Internacional e ao 14ํㅡㄹ ENEMET - Encontro Nacional de Estudantes de Engenharia Metalúrgica, de Materiais e de Minas,21 a 25 de julho de 2014, São Paulo, SP, Brasil.
} 


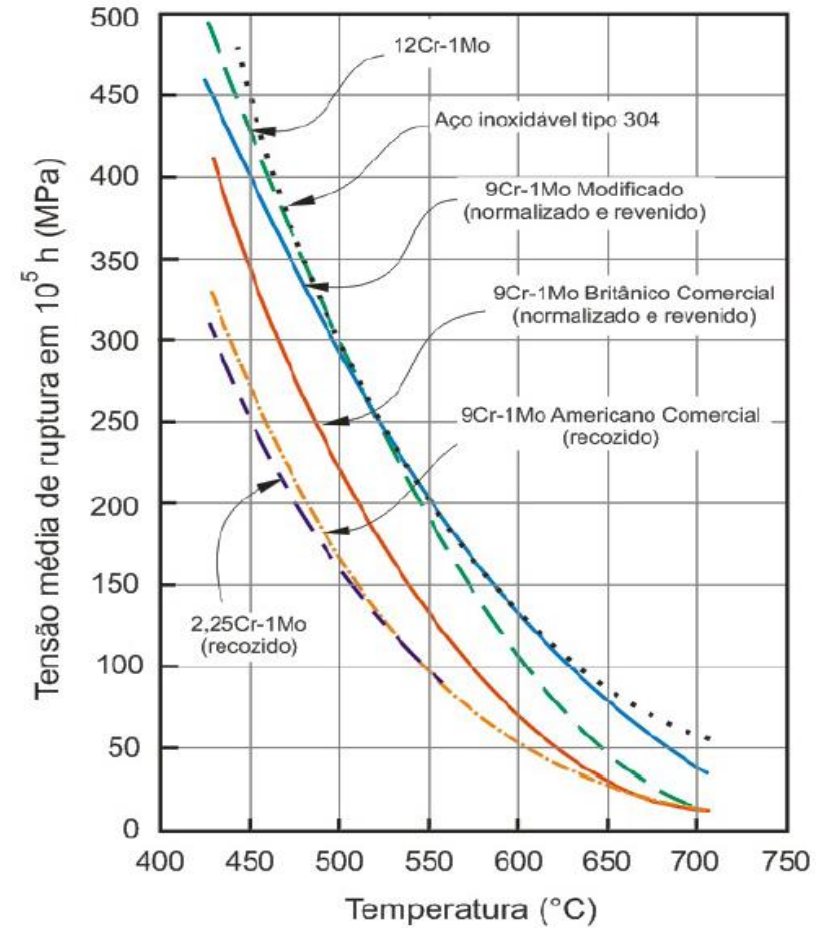

(a)

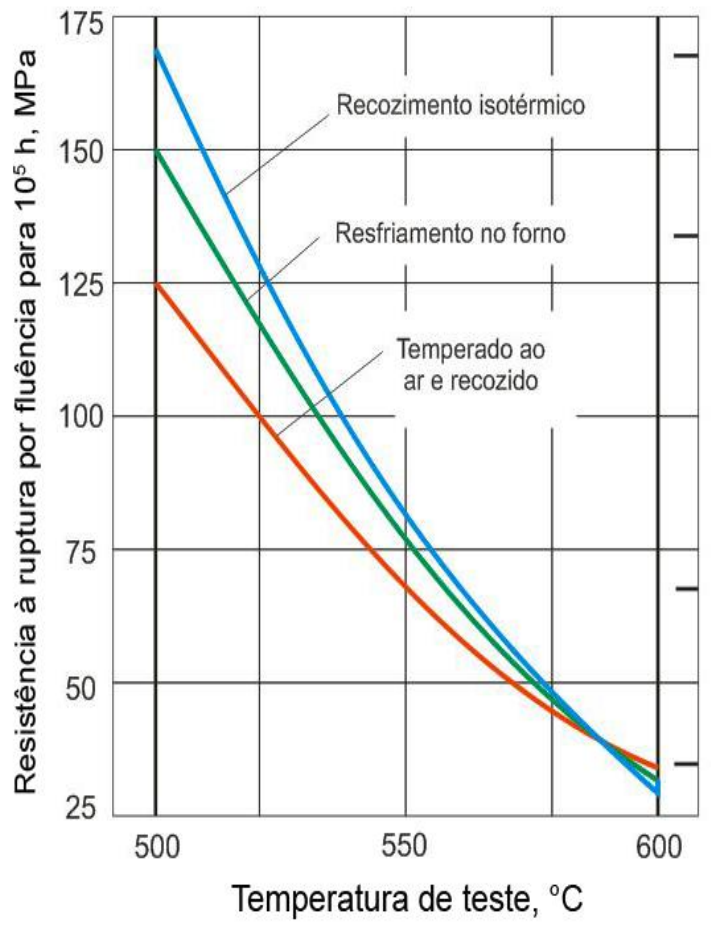

(b)

Figura 5. (a) Variação da tensão de ruptura a fluência com a temperatura para vários aços. (b) Influência do tratamento térmico sobre a resistência à ruptura por fluência para $10^{5} \mathrm{~h}$ em um aço $2,25 \mathrm{Cr}$ 1Mo. (Adaptado de $[15,18]$ )

Para melhorar as propriedades de resistência à fluência dos aços ferríticos Cr-Mo, estudos vem sendo realizados com o propósito de estudar a substituição total e/ou parcial do Mo pelo W, juntamente com a adição de outros elementos de liga, como 0 $\mathrm{Nb}$ e o $\mathrm{V}$, que são formadores de finos precipitados, aumentando a resistência mecânica em temperaturas elevadas e favorecendo a permanência do W e do Mo em solução sólida, além da adição de $B$ e a redução no teor de $C$. Os primeiros estudos dos aços com as características descritas acima indicam aços com melhores propriedades mecânicas que os aços convencionais Cr-Mo, assim destacando o grande potencial dessa nova classe de aços ferríticos.

\section{DISCUSSÃo}

Os aços Cr-Mo são ligas que tem grãos cristalinos contendo ao mesmo tempo átomos de soluto substitucionais e intersticiais em solução sólida, partículas de segunda fase dispersas no interior do grão e presença de precipitados. A resistência à fluência desses aços se deve tanto ao endurecimento por solução sólida, como ao endurecimento por precipitação.

Tomando como exemplo o aço do tipo P91, com composição química conforme a Tabela 1, de acordo com as especificações da ASTM, ele é normalizado a $1038^{\circ} \mathrm{C}$ e revenido a $732^{\circ} \mathrm{C}$ [17]. Na composição desse aço, o molibdênio é o principal elemento responsável pelo aumento da resistência à fluência como também o cromo, quando presente em solução sólida ou em precipitados. Segundo Dieter [1], a adição de elementos formadores de solução sólida pode aumentar a resistência através de vários mecanismos como a segregação nas falhas de empilhamento, interações

\footnotetext{
* Contribuição técnica ao $69^{\circ}$ Congresso Anual da ABM - Internacional e ao 14ํㅡㄹ ENEMET - Encontro Nacional de Estudantes de Engenharia Metalúrgica, de Materiais e de Minas,21 a 25 de julho de 2014, São Paulo, SP, Brasil.
} 
elásticas de átomos com as discordâncias móveis, interação com lacunas e degraus de discordâncias e a segregação nos contornos de grão.

O carbono e o nitrogênio atuam como átomos de soluto intersticiais, juntamente com vanádio e nióbio, formando carbonetos e nitretos que se distribuem finamente na microestrutura desses aços podendo estabilizar outros carbetos ou simplesmente atuar no refino do grão. Este efeito combinado dos precipitados de vanádio e nióbio gera uma fina distribuição ao longo da matriz que pode dificultar a movimentação das discordâncias e reduzir o efeito da recuperação e da recristalização a altas temperaturas elevando assim a resistência à fluência destes aços. Esses precipitados atuam de duas maneiras distintas para retardar o movimento das discordâncias. Esses precipitados atuam de duas maneiras distintas para retardar o movimento das discordâncias, cortando-as ou contornando essas discordâncias.

Nos ensaios de fluência essas ligas são submetidas a um envelhecimento, que ocorre em função da temperatura e do tempo. Este fenômeno está associado à interação das discordâncias com os átomos de soluto. A altas temperaturas e durante um tempo, há difusão dos átomos intersticiais para formar atmosferas em discordâncias (atmosferas de Cottrell). As discordâncias ficam aprisionadas pelas atmosferas de átomos, que as imobilizam ou ancoram, sendo necessário maior energia para liberta-las. Para que haja a movimentação das discordâncias, algumas teorias são utilizadas, como o deslizamento das discordâncias e a escalagem das discordâncias e os efeitos da difusão na fluência. Como a escalagem depende da difusão de lacunas em direção às discordâncias aresta, a deformação por fluência resultante da escalagem deve também envolver a energia de ativação para a autodifusão. Como se trata de um processo relativamente lento cabe a ele o controle da taxa de fluência. Temperaturas elevadas podem ainda tornar operativos novos mecanismos de deformação, como a mudança do sistema de deslizamento ou a introdução de sistemas de deslizamento adicionais.

Miranda [4] afirma que entre os mecanismos básicos de deformação por fluência que a escalagem é o mais estudado, existindo diversos modelos para explicá-lo, sendo o principal aquele que relaciona este fenômeno à absorção de lacunas. A taxa mínima de fluência depende da frequência com que ocorrem flutuações de posição, originadas pela excitação térmica, e assim capazes de permitir o movimento dos átomos ultrapassando os obstáculos a partir de suas posições de equilíbrio.

\section{CONCLUSÃO}

Com o objetivo de apresentar os mecanismos de deformação plástica por fluência aplicado a classe dos aços Cr-Mo, foram levantados conceitos referentes à fluência, bem como a sua curva típica. Foram abordados os principais mecanismos de deformação por fluência (deslizamentos de discordância, fluência por discordâncias, fluência por difusão e fluência por deslizamento de contorno grão), os mecanismos para aumentar a resistência das ligas por fluência, os tipos de ligas empregadas a altas temperaturas, e o estudo dos mecanismos de deformação plástica por fluência para os aços ferriticos Cr-Mo pertencentes à norma ASTM A-335, submetidos a tratamento térmico de 500 a $600^{\circ} \mathrm{C}$, tomando como exemplo o aço P91. Dentre os mecanismos básicos de deformação por fluência, a escalagem é o mais estudado, e como se trata de um processo relativamente lento, por depender da difusão no estado sólido, cabe a esse mecanismo o controle da taxa de fluência.

\section{Agradecimentos}

* Contribuição técnica ao 69ำ Congresso Anual da ABM - Internacional e ao 14ํㅡㄹ ENET - Encontro Nacional de Estudantes de Engenharia Metalúrgica, de Materiais e de Minas,21 a 25 de julho de 2014, São Paulo, SP, Brasil. 
Os autores agradecem à Fundação de Amparo à Pesquisa do Estado do Amazonas - FAPEAM e ao Conselho Nacional de Desenvolvimento Científico e Tecnológico CNPq (Processo No 132120/2013-5) pelo apoio financeiro.

\section{REFERÊNCIAS}

1 Dieter GE. Mechanical metallurgy. SI Metric ed. Londres: McGraw-Hill; 1988.

2 Mao H, Mahadevan S. Reliability analysis of creep-fatigue failure. International Journal of Fatigue. 2000;22:789-797.

3 Souza SA. Ensaios Mecânicos de Materiais Metálicos. Fundamentos teóricos e práticos.5a ed. São Paulo: Ed. Edgard Blucher; 1982.

4 Miranda PEV, Pascual R, Silveira TL. Propriedades Mecânicas em Altas Temperaturas. Rio de Janeiro: Acete; 1983.

5 Chiaverini V. Tecnologia Mecânica, v.1. 2ª ed. São Paulo: McGraw - Hill; 1986.

6 Evans HE. Mechanisms of Creep Fracture. London and New York: Elsevier Applied Science Publishers; 1984.

7 Van Vlack LH. Princípios de Ciência dos Materiais. 1aㅡ ed. São Paulo: Editora Edgard Blücher Ltda; 2000.

8 Reed-Hill RE. Physical Metallurgy Principles. 2 $2^{\mathrm{a}}$ ed. Londres; 1973.

9 Kim B, Hiraga K. Contribution of Grain Boundary Sliding in Diffusional Creep. Scripta Materialia. 2000;42:451-456.

10 Oliveira TP. Estudo da Soldagem Dissimilar entre os Aços ASTM P91 e DIN 14MOV6.3 para Componentes Sujeitos a Fluência [dissertação de mestrado]. Florianópolis: Centro Tecnológico, Programa de Pós-Graduação em Engenharia Mecânica, Universidade Federal de Santa Catarina; 2010.

11 Lundin CD, Liu P, Cui Y. A Literature Review on Characteristics of High Temperature Ferritic Cr-Mo steels and weldments. Welding Research Council Bulletin. 2000; 454:136.

12 Lisboa MB. Nova Geração de Aços Ferríticos Fe-Cr-W(V) - Análise da Evolução Microestrutural e Comportamento Mecânico Sob Fluência [Ph.D. Thesis], Rio de Janeiro: COPPE, UFRJ; 2007.

13 Yin Y, Faulkner RG. Physical and Elastic Behaviour of Creep-Resistant Steels. In: Creep-resistant steels, 1 ed., chapter 6, Cambridge, England: Woodhead and Maney Publishing; 2008.

14 Mendes MC. Efeito da Redução do Teor de C sobre a Resistência à Fluência de Juntas Soldadas de um Aço do Tipo CrMoW(V) [dissertação de mestrado]. Rio de Janeiro: COPPE, Programa de Engenharia Metalúrgica e de Materiais, UFRJ; 2012.

15 Davis, Joseph R. ASM Specialty Handbook Heat-Resistant Material. ASM International. 1997.

16 Masuyama F. History of Power Plants and Progress in Heat Resistant Steels. The Iron and Steel Institute of Japan, v.41, n. 6, pp. 612-625; 2001.

17 ASTM. ASTM A 335/A 335M - 06: Standard Specification for Seamless Ferritic AlloySteel Pipe for High-Temperature Service. West Conshohocken; 2006.

18 Sikka VK. Substitution of Modified 9Cr-1Mo Steel for Austenitic Stainless Steels. In: Workshop on conservation and substitution technology for critical materials, Nashville, TN, USA; 1982.

\footnotetext{
* Contribuição técnica ao $69^{\circ}$ Congresso Anual da ABM - Internacional e ao 14ํㅡㄹ ENEMET - Encontro Nacional de Estudantes de Engenharia Metalúrgica, de Materiais e de Minas,21 a 25 de julho de 2014, São Paulo, SP, Brasil.
} 